Supporting information for the manuscript entitled

\title{
Insights into the Moisture Scavenging Properties of different Types of Starch in Tablets containing a Moisture Sensitive Drug
}

\author{
Natalia Veronica, Tze Ning Hiew ${ }^{\circledR}$, Celine Valeria Liew, Paul Wan Sia Heng* \\ GEA-NUS Pharmaceutical Processing Research Laboratory, Department of Pharmacy, \\ National University of Singapore, 18 Science Drive 4, Singapore 117543, Singapore \\ ${ }^{\circledR}$ Present address: Department of Industrial and Physical Pharmacy, College of Pharmacy, \\ Purdue University, 575 Stadium Mall Drive, West Lafayette, IN 47907-2091, USA
}

*Corresponding author: P.W.S Heng, GEA-NUS Pharmaceutical Processing Research Laboratory, Department of Pharmacy, National University of Singapore, 18 Science Drive 4, Singapore 117543, Singapore. Tel: +65 65162930; fax: +65 67791554 .

E-mail address: phapaulh@nus.edu.sg 


\section{ASSOCIATED CONTENT}

Supporting information
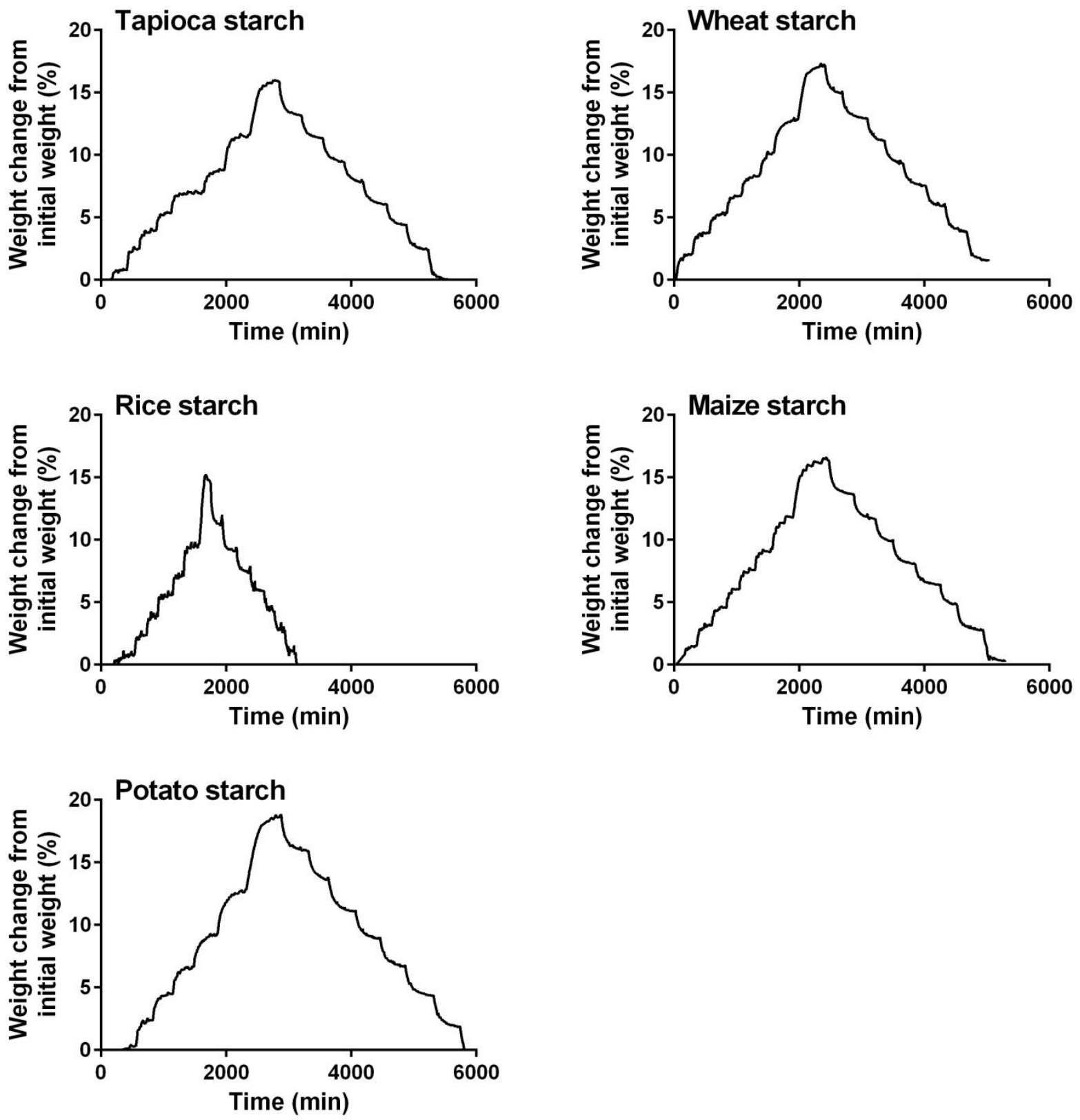

Figure S1. Weight change over time under a given RH condition for different types of starch. 